\title{
The relationship between aerosol and cloud drop number concentrations in a global aerosol microphysics model
}

\author{
K. J. Pringle ${ }^{1, *}$, K. S. Carslaw ${ }^{1}$, D. V. Spracklen ${ }^{1}$, G. M. Mann ${ }^{1}$, and M. P. Chipperfield ${ }^{1}$ \\ ${ }^{1}$ Institute for Climate and Atmospheric Science, School of Earth and Environment, University of Leeds \\ *now at: Max-Planck-Institute for Chemistry, Mainz, Germany
}

Received: 4 November 2008 - Published in Atmos. Chem. Phys. Discuss.: 30 January 2009

Revised: 9 June 2009 - Accepted: 9 June 2009 - Published: 22 June 2009

\begin{abstract}
Empirical relationships that link cloud droplet number $(\mathrm{CDN})$ to aerosol number or mass are commonly used to calculate global fields of $\mathrm{CDN}$ for climate forcing assessments. In this work we use a sectional global model of sulfate and sea-salt aerosol coupled to a mechanistic aerosol activation scheme to explore the limitations of this approach. We find that a given aerosol number concentration produces a wide range of $\mathrm{CDN}$ concentrations due to variations in the shape of the aerosol size distribution. On a global scale, the dependence of CDN on the size distribution results in regional biases in predicted CDN (for a given aerosol number). Empirical relationships between aerosol number and CDN are often derived from regional data but applied to the entire globe. In an analogous process, we derive regional "correlation-relations" between aerosol number and CDN and apply these regional relations to calculations of $\mathrm{CDN}$ on the global scale. The global mean percentage error in $\mathrm{CDN}$ caused by using regionally derived $\mathrm{CDN}$-aerosol relations is 20 to $26 \%$, which is about half the global mean percentage change in $\mathrm{CDN}$ caused by doubling the updraft velocity. However, the error is as much as $25-75 \%$ in the Southern Ocean, the Arctic and regions of persistent stratocumulus when an aerosol-CDN correlation relation from the North Atlantic is used. These regions produce much higher $\mathrm{CDN}$ concentrations (for a given aerosol number) than predicted by the globally uniform empirical relations. CDNaerosol number relations from different regions also show very different sensitivity to changing aerosol. The magnitude of the rate of change of CDN with particle number, a measure of the aerosol efficacy, varies by a factor 4 . CDN
\end{abstract}

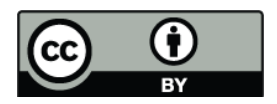

Correspondence to: K. J. Pringle (pringle@mpch-mainz.mpg.de) in cloud processed regions of persistent stratocumulus is particularly sensitive to changing aerosol number. It is therefore likely that the indirect effect will be underestimated in these important regions.

\section{Introduction}

The prediction of cloud droplet number (CDN) in a global aerosol model is a challenging task, but is vital if we are to reduce the uncertainty surrounding the quantification of the aerosol indirect effect. The number of cloud droplets formed in a rising air parcel is dependent on the number, size and chemical composition of the aerosol particles and the meteorological conditions (i.e. the updraft velocity). These factors can vary widely between different regions and even between different clouds within the same region.

Because of the limited amount of aerosol information carried in climate models the calculation of droplet number has been greatly simplified (Lohmann and Feichter, 2005). One widely used approach is to define one or more empirical relationships between aerosol number or mass and CDN based on observations at cloud base. Empirical relations offer a simple and effective way of predicting the number of cloud droplets that will form for a given aerosol concentration and have been used extensively to calculate the aerosol indirect effect. However empirical schemes have a number of limitations which must be considered:

1. Empirical relations are derived from measurements taken in a limited geographical region and present day conditions but they are extrapolated to the global scale as well as past and future atmospheric conditions. Regional and long term variations in the aerosol size

Published by Copernicus Publications on behalf of the European Geosciences Union. 
distribution and composition may result in changes to the relationship between the bulk quantities aerosol number, mass and CDN.

2. Several empirical relations have been published based on a range of observations. The differences between these relations increases the uncertainty in empirically based forcing estimates as the forcing calculated for a given aerosol loading depends on the relation used. For example, Kiehl et al. (2000) predicted the indirect forcing to range from -0.68 to $-1.78 \mathrm{Wm}^{-2}$, depending on the empirical relation used.

3. Empirical relations bypass the detailed microphysical processes that control CDN. It is therefore unsuitable for use as a tool to examine the factors in the aerosol population that are important in controlling CDN.

The alternative to an empirical relation is to calculate cloud drop number in a physically based or mechanistic way (e.g., Abdul-Razzak and Ghan, 2000; Nenes and Seinfeld, 2003; Fountoukis and Nenes, 2005; Ming et al., 2006). In this approach the modeled aerosol particle size distribution is used to calculate an activation diameter for a particular cloud parcel updraft speed. This normally involves an approximate solution to the Kohler equation. The advantage of a mechanistic approach is that it connects the physical and chemical properties of the aerosol size distribution to cloud drop number in a physical way. The major disadvantages are that it requires more aerosol microphysics information to be carried in the global model and it requires a realistic cloud parcel updraft speed, which cannot be resolved in a global model. To get around the latter problem, previous models have used the large-scale updraft velocity combined with the turbulent kinetic energy to define the updraft or have used a constant value (e.g., Meskhidze et al., 2007; Chen and Penner, 2005; Lohmann et al., 1999).

Although the limitations of empirical schemes are appreciated, they are still widely used in climate modeling studies (e.g., Bauer et al., 2008; Ma et al., 2008; Menon and Rotstayn, 2007; Rotstayn et al., 2007; Quaas et al., 2006; Verma et al., 2006; Ming et al., 2005). Of the 20 studies of the cloud albedo effect considered in the Intergovernmental Panel on Climate Change's Forth Assessment Report (Forster et al., 2007), half rely entirely on empirical relations to calculate CDN. Of the remaining models, two use Köhler theory to describe activation but prescribe a supersaturation depending on cloud type (Kristjansson, 2002; Kristjansson et al., 2005), thus in effect they use the cloud condensation nuclei (CCN) concentration as a proxy for CDN. The studies of Lohmann et al. (2000) and Chuang et al. (2002) use a parameterisation that takes the aerosol size distribution, composition and updraft velocity into account through the use of an "activation parameter". Only the works of Penner et al. (2006), Takemura et al. (2005), Chen and Penner (2005) and Ghan et al. (2001) use a mechanistic treatment of aerosol activation that is able to capture feedbacks between the aerosols and the supersaturation attained in a cloud. Of these, all but Chen and Penner (2005) use the mechanistic parameterisation of Abdul-Razzak and Ghan (2002, 2000); Abdul-Razzak et al. (1998) (hereafter ARG), while Chen and Penner (2005) uses ARG and the parameterisation of Nenes and Seinfeld (2003) (hereafter NS03).

One previous study (Meskhidze et al., 2007) has compared a mass-based empirical relation and a mechanistic parameterisation of CDN and calculated a $20 \%$ change in aerosol indirect effect, which is quite small compared to the intermodel spread in calculated forcings.

In this work we compare various empirical aerosol-CDN relations to a mechanistic treatment of CDN (NS03) within a global size-resolving aerosol microphysics model. Our emphasis is on the regional variability in the aerosol-CDN relation and in particular the regional impact of assuming a single "global" relationship between aerosol number and CDN. We show that none of the frequently used aerosol-CDN relations is able to capture regional variations in CDN caused by systematic variations in the aerosol size distribution. We restrict the study to variations in CDN at cloud base for an assumed updraft velocity and do not attempt to calculate prognostic droplet number taking into account collision-coalescence and other cloud microphysical processes.

In Sect. 2 we begin by showing global fields of CCN, CDN and maximum cloud supersaturation. In Sect. 3 we compare the mechanistic results with an empirical prediction and explore the geographical biases and microphysical causes. In Sect. 4 we examine the assumption that an aerosol number - CDN relationship derived from data taken in a limited geographical area can be applied to the calculation of global fields of CDN.

\subsection{Model description}

We use the Global Model of Aerosol Processes (GLOMAP), which is an extension of the TOMCAT chemical transport model (Chipperfield, 2006; Stockwell and Chipperfield, 1999). GLOMAP is described in Spracklen et al. (2005a), so is only briefly summarised here. The aerosol distribution is described using a sectional moving-center scheme with 20 aerosol bins spanning dry diameters from about $3 \mathrm{~nm}$ to $25 \mu \mathrm{m}$. Two moments are simulated in each size section (particle number density and mass per particle). The use of a sectional (or bin-resolved) aerosol scheme is advantageous for this study as sectional schemes (unlike modal schemes) do not make assumptions about the shape of the size distribution (Zhang et al., 2002). The model includes processes of binary homogeneous nucleation, condensation, coagulation, and size-resolved dry and wet deposition. The binary homogeneous nucleation scheme used is that of Kulmala et al. (1998). Other nucleation processes contribute to particle formation in the troposphere, thus the model may underestimate particle number, particularly at smaller sizes and in 
continental regions (see Spracklen et al., 2006). To account for sub-grid nucleation, $2 \%$ of $\mathrm{SO}_{2}$ emissions are assumed to emitted in particulate form (Spracklen et al., 2005a; Adams and Seinfeld, 2003). The model data presented here is for October 2001, the model was spun up for three months before this time.

In this study GLOMAP is restricted to sea salt and sulfate aerosol, which are simulated in one internally mixed size distribution (as used in Spracklen et al., 2005a,b, 2007; Korhonen et al., 2008). Model runs have a resolution of $2.8^{\circ} \times 2.8^{\circ}$ with 31 hybrid $\sigma$-p levels extending from the surface to $10 \mathrm{hPa}$. Large-scale atmospheric transport is specified from the European Centre for Medium-Range Weather Forecasts (ECMWF) analyses at 6-hourly intervals. The model includes emissions of anthropogenic $\mathrm{SO}_{2}$ representative of the year 1985 (Benkovitz, 1996), volcanic $\mathrm{SO}_{2}$, dimethyl sulfide and sea salt. For the calculation of in-cloud processing, monthly mean low cloud cover is diagnosed from the ISCCP climatology (http://isccp.giss.nasa.gov/).

The model treats sulfate and sea-salt aerosol only. The lack of other aerosol components such as elemental and organic carbon means that the model will underestimate aerosol number in many polluted regions. However, a comparison with observations (Spracklen et al., 2007) showed that the model simulates realistic distributions of aerosol number and size in most remote marine regions (where this paper will focus), with only a small improvement in the comparison when emissions of carbonaceous particles were included.

The chemical composition of an aerosol particle can affect the activation of the particle. This additional dimension to the aerosol activation process is not captured in these simulations, as we only treat hydrophillic particles. Although neglecting the effect of particle composition is a simplification, it is reasonable as a first approach as Dusek et al. (2006) have shown that the cloud condensation nuclei concentration is mainly determined by the aerosol number size distribution, with the aerosol composition playing a secondary role. This is because the amount of soluble mass in an aerosol particle changes with the third power of particle diameter but changes only linearly with a change in the soluble mass fraction. Thus a small change in diameter has a larger effect on the amount of soluble mass (and thus the activation potential) than an equivalent change in the soluble mass fraction (see e.g. Andreae and Rosenfeld (2008)).

Cloud droplet number concentrations, activation diameters and maximum supersaturations are calculated as model diagnostics using the NS03 scheme, which has been shown to compare well with parcel model simulations (Nenes and Seinfeld, 2003; Fountoukis and Nenes, 2005). The NS03 parameterisation is called at the end of each microphysical model time step, i.e. every $7.5 \mathrm{~min}$ (Spracklen et al., 2005a). CDN concentrations are calculated at an altitude of $920 \mathrm{hPa}$, corresponding approximately to the base of low stratocumulus clouds. Because we are not calculating the radiative forc- ing we do not attempt to quantify the reduction in CDN at cloud top caused by droplet collision-coalescence. CDN concentrations are calculated using a globally constant updraft speed of either 0.15 or $0.3 \mathrm{~ms}^{-1}$, representative of typical stratocumulus updrafts. In reality, updraft varies both within and between clouds, although Meskhidze et al. (2005) and Fountoukis et al. (2007) showed that the use of an average updraft velocity is sufficient to capture the mean CDN produced from a range of updrafts. As we show, the conclusions of our study are not dependent on the updraft considered.

\section{Global fields of cloud droplet number}

The global distribution of CDN, cloud condensation nuclei $(\mathrm{CCN})$ at $0.2 \%$ supersaturation, and the maximum in-cloud supersaturation $\left(\mathrm{S}_{\mathrm{max}}\right)$ for October 2001 are shown in Fig. 1. "CCN" is equivalent to the number concentration of particles with dry diameters $>70 \mathrm{~nm}$, which is the approximate activation diameter of ammonium sulfate aerosol at $0.2 \%$ supersaturation. CDN concentrations are shown for every grid box, regardless of the presence of cloud.

The global CDN distribution reflects the distribution of $\mathrm{CCN}$, which has maxima over the polluted regions of $\mathrm{N}$. America, Europe and Asia where the anthropogenic sulfur loading is largest. CDN concentrations are broadly in line with observations; in clean marine regions concentrations of $25-100 \mathrm{~cm}^{-3}$ are predicted ( $\mathrm{cf}$ an average of $40 \mathrm{~cm}^{-3}$, Bennartz, 2007), this increases to $100-400 \mathrm{~cm}^{-3}$ in polluted marine regions (cf 170-500, Meskhidze et al., 2005; Menon et al., 2003). Polluted continental CDN concentrations are underestimated $\left(300-600 \mathrm{~cm}^{-3}\right)$ compared to observed values (350 to $1200 \mathrm{~cm}^{-3}$, Fountoukis et al., 2007), this may be due either to the lack of additional species in our model or the relatively low updrafts chosen (which are most appropriate for marine regions).

The maximum supersaturation $\left(\mathrm{S}_{\max }\right)$ predicted by NS03 is a function of the competing effects of water vapor production due to the cooling of rising air and water vapor loss due to condensation onto activated aerosol. The $\mathrm{S}_{\max }$ distribution is the inverse of the $\mathrm{CCN}$ distribution; when there is an abundance of $\mathrm{CCN}$ there are lots of sites for water vapor to condense onto, thus the $S_{\max }$ is suppressed. In general the $S_{\max }$ calculated is in the range suggested by observations (e.g. Martin et al. (1994) observed values of $S_{\max }$ of $0.35 \pm 0.13$ in continental regions and up to 0.8 for marine regions), although the model tends to over-predict the magnitude of $S_{\max }$ in Arctic and Antarctic regions.

These plots show the limitation of parameterising CDN by prescribing a uniform supersaturation. For example, Kristjansson (2002) prescribe a constant $S_{\max }$ in all stratiform and all convective clouds (also used by Kristjansson et al., 2005; Kirkevag et al., 2008). With a globally uniform updraft velocity, the maximum supersaturation attained in a rising air parcel varies throughout the globe as high aerosol loadings 

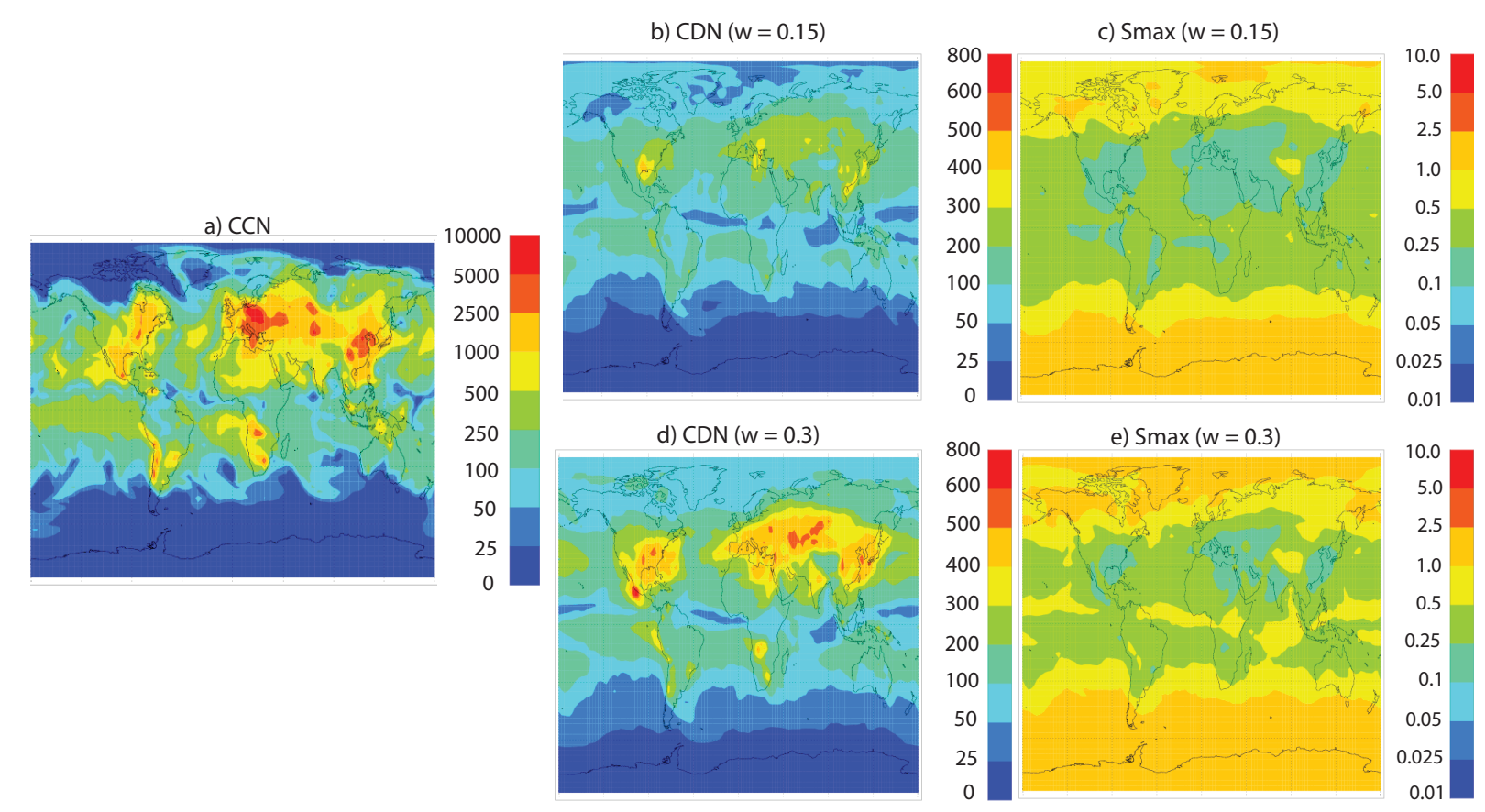

Fig. 1. (a) Global fields of $\mathrm{CCN}$ at $0.2 \%$ supersaturation $\left(\mathrm{cm}^{-3}\right)$; (b) $\mathrm{CDN}$ concentration $\left(\mathrm{cm}^{-3}\right)$ predicted using NS03 and an updraft velocity $(w)$ of $0.15 \mathrm{~ms}^{-1}$; (c) Maximum supersaturation predicted $(w=0.15)$; (d) and (e) are the same as (b) and (c) but for an updraft of $0.3 \mathrm{~ms}^{-1}$. The figures show monthly mean field for October 2001 and an altitude of $920 \mathrm{hPa}$.

can suppress $S_{\max }$. Thus in a polluted region, a smaller fraction of the available $\mathrm{CCN}$ will activate (compared to a clean region with lower aerosol loading). Allowing the updrafts to vary between regions would change the distribution of $S_{\max }$ but would not change the dependence of $S_{\max }$ on the aerosol distribution. Assuming that one average supersaturation is representative of all regions of the atmosphere will typically lead to an underestimation of CDN in remote regions and an overestimation of $\mathrm{CDN}$ in polluted regions.

\section{Comparison of mechanistic and empirical CDN fields}

Figure 2 compares the mechanistic CDN calculation with several empirical relations based on aerosol mass (Lowenthal et al., 2004; Boucher and Lohmann, 1995) and number (Gultepe and Isaac, 1999; Jones et al., 1994). The non seasalt (nss)-sulfate mass was derived in the model by calculating the total aerosol mass (sulfate and sea-salt), and subtracting the mass of sea-salt derived from a sea-salt only simulation for the same time period. In the aerosol number/CDN plots (top row), only aerosol particles with diameter $\mathrm{D}_{p}>50 \mathrm{~nm}$ were counted, to be consistent with the measurements on which the empirical relations are based (Jones et al., 1994). In regions with very low aerosol loading particles smaller than $50 \mathrm{~nm}$ can activate, especially if the updraft is reasonably large. This leads to a small number of points on the left hand side of the plots where $\mathrm{CDN}>0$ but aerosol number $\left(\mathrm{D}_{p}>50 \mathrm{~nm}\right)$ is zero. This is a limitation of using a number-based empirical relation; aerosol number is typically dominated by very small particles that cannot activate, thus there is a need to only consider particles over a certain size, but choosing an arbitrary cut-off is limited as the size above which aerosol can activate is dependent on the conditions.

In general, the dependence on aerosol number predicted using the empirical scheme compares well with the physically based CDN fields. The empirical relations and the model results show a sub-linear (slope of $<1: 1$ ) dependence of CDN on aerosol number which is caused by the suppression of supersaturation at high aerosol number. Within the range of observations $\left(100-10000 \mathrm{ng} \mathrm{m}^{-3}\right.$ ), the dependence of nss-sulfate mass is also captured.

Increased updraft velocity is not found to alter the dependence of CDN on nss-sulfate mass; there is a simple "shift" in the CDN spectrum to larger values as updraft is increased. The dependence of CDN on aerosol number, however, is dependent on the updraft velocity. The dependence of CDN on aerosol number, however, is dependent on the updraft velocity. In the lower updraft case, the rate of change of CDN with aerosol number nears zero above moderate aerosol loadings. In the higher updraft case, the rate of change of CDN with aerosol number decreases with increasing aerosol number, but is always above zero. In the $0.15 \mathrm{~ms}^{-1}$ case, an increase in aerosol loading above $400 \mathrm{~cm}^{-3}$ results in only a small increase in $\mathrm{CDN}$ but at the higher updraft velocity an increase 

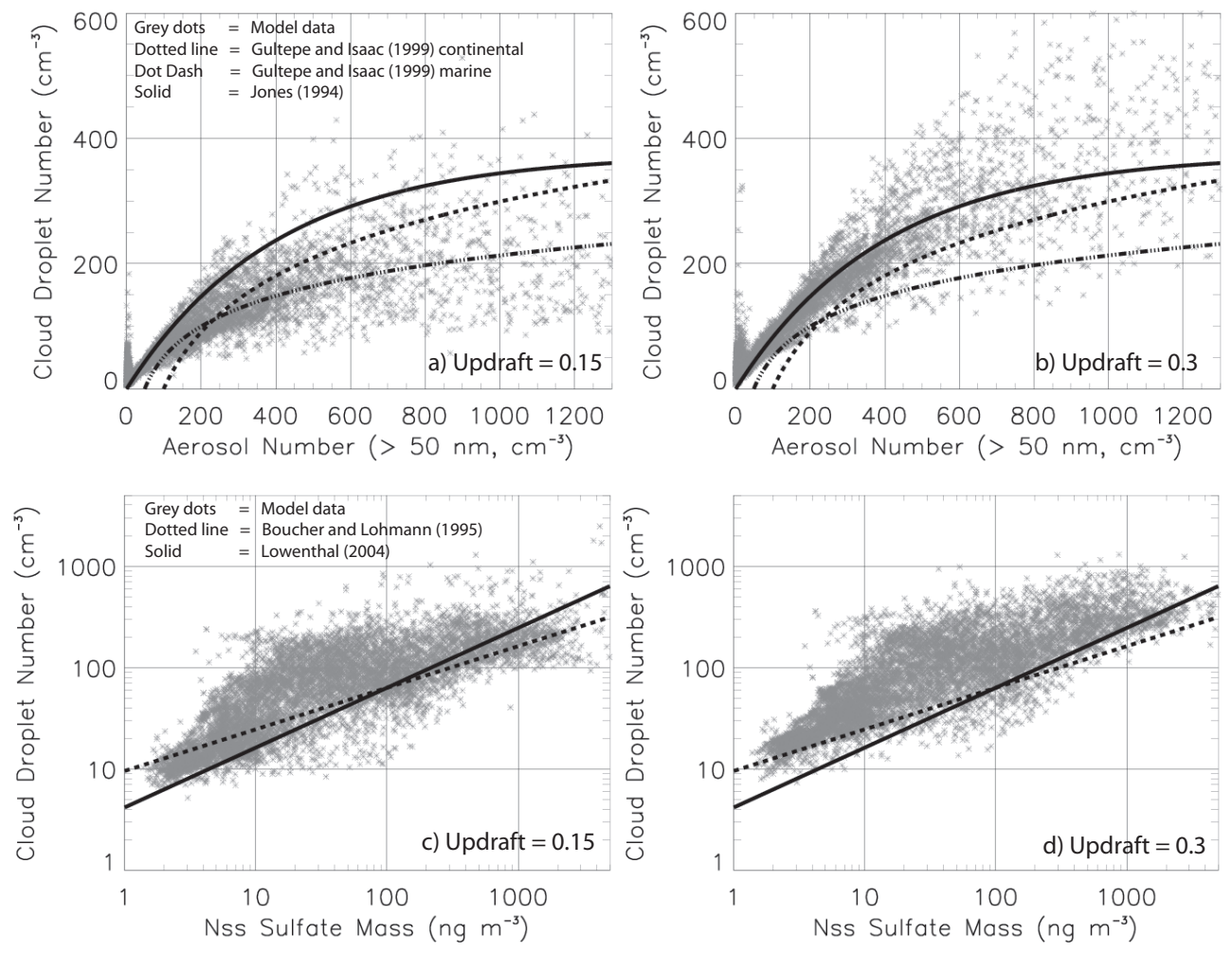

Fig. 2. Simulated dependence of CDN on aerosol number (top row) and nss-sulfate mass (bottom row) calculated at two updraft velocities $\left(0.15\right.$ and $\left.0.3 \mathrm{~ms}^{-1}\right)$. Model data (grey dots) is taken from all model grid boxes in one model level (average pressure level of $920 \mathrm{hPa}$ ). For the number plots (top row), the over plotted lines correspond to; the empirical relationship of Jones et al. (1994) (solid), Gultepe and Isaac (1999) for marine (dash-dot) and continental regions (dotted). For the mass plots (bottom row), the lines correspond to; Lowenthal et al. (2004) for solid, and Boucher and Lohmann (1995) for dotted.

in aerosol number above $400 \mathrm{~cm}^{-3}$ results in a significant increase in CDN. This sensitivity to updraft is missed in empirical schemes which are produced by averaging over all updraft velocities measured. This sensitivity may be globally important as updraft velocities can vary systematically between regions (e.g. continental updrafts are typically larger than marine). Thus the updraft velocity is important not just for the absolute $\mathrm{CDN}$ concentration, but also for the change in $\mathrm{CDN}$ arising from a change in aerosol number, which is important for the calculation of the first aerosol indirect effect. The use of different empirical relations for marine and continental clouds (e.g. Gultepe and Isaac, 1999), may capture some of this effect.

\subsection{Impact of the size distribution on CDN}

Figure 2 shows that a given total aerosol number can result in a wide range of CDN concentrations, which is not predicted by a single empirical relation, but is similar to the variability apparent in observations used to construct the empirical relations. In the observations compiled by Boucher and Lohmann (1995) CDN varied by an order of magnitude for a single nss-sulfate aerosol mass and Ramanathan et al. (2001) found inter-regional variations in $\mathrm{CDN}$ of a factor 2 for a given aerosol number. However, it is important to note that the variability cannot be compared quantitatively because of the very different spatial and temporal sampling in the observations and model. In observations it is difficult to determine how much of the variation is due to meteorological factors (e.g., changes in updraft speed), or measurement artifacts, and how much is due to systematic differences in the aerosol distribution between regions (e.g. McComiskey and Feingold, 2008), although Hallberg et al. (1998) found that the scatter can exceed that predicted by measured variations in updraft velocity.

In this work, the scatter in the predicted CDN concentrations arises solely from the shape of the aerosol size distribution. For any total aerosol number concentration (or nsssulfate mass concentration) there are several possible aerosol size distributions, each of which corresponds to a unique solution to the equations governing droplet number and supersaturation. Figure 3 shows the average aerosol size distribution contributing to $\mathrm{CDN}$ concentrations that are larger (or smaller) than two reference values: 


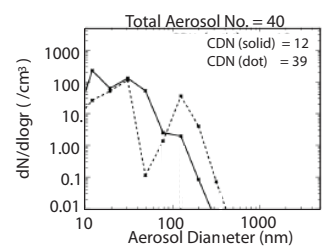

Solid line $=\mathrm{CDN}<\mathrm{CDN}_{15}$ Dotted line $=\mathrm{CDN}>\mathrm{CDN}_{85}$
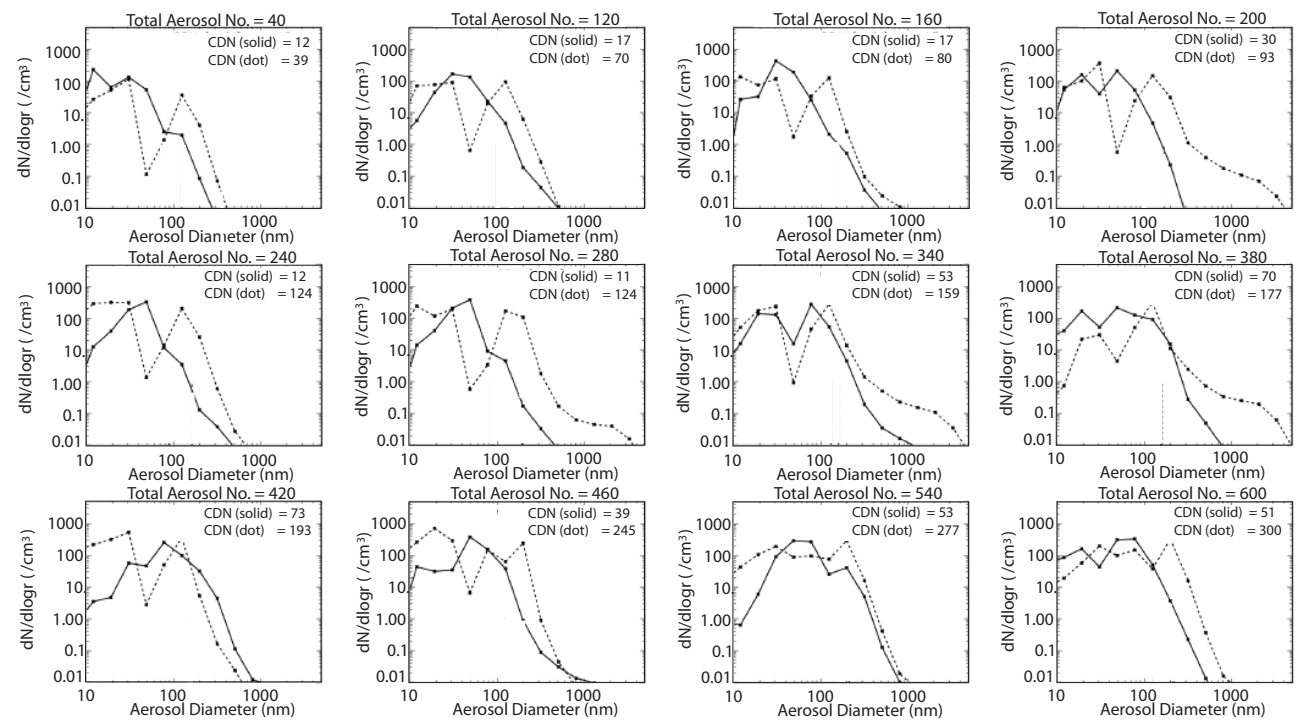

Fig. 3. Aerosol number distributions for a range of total aerosol number concentrations $\left(\mathrm{D}_{p}>50 \mathrm{~nm}\right)$, see plot titles for details. The average aerosol number distributions leading to a $\mathrm{CDN}$ that is (i) smaller than the 15 th percentile $\left(\mathrm{CDN}_{15}\right)$ (solid line) and (ii) larger than the 85 th percentile $\left(\mathrm{CDN}_{85}\right)$ (dotted line) are shown.

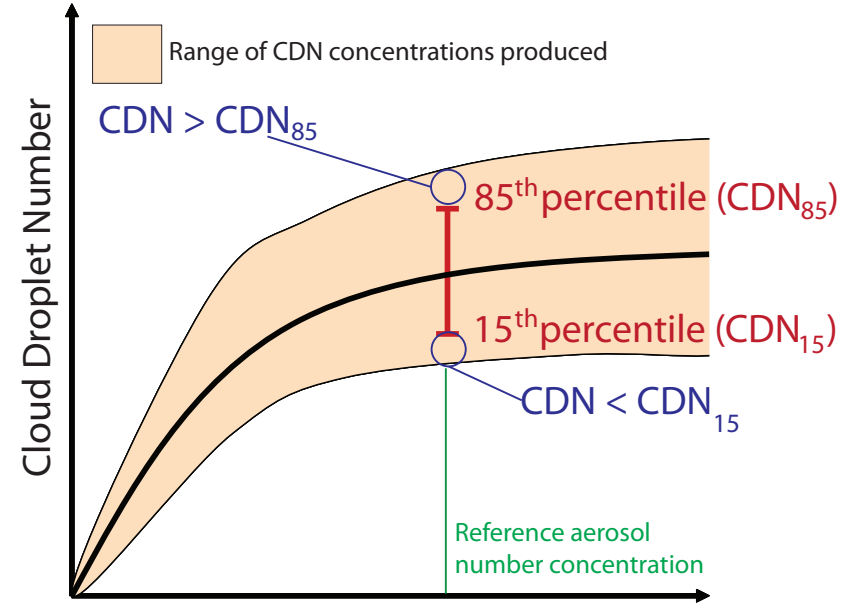

Aerosol Number Concentration

Fig. 4. Schematic showing the definition of the terms $\mathrm{CDN}_{15}$ and $\mathrm{CDN}_{85}$; the 15th and 85th percentiles and the regions where CDN is either above or below these reference values.

1. $\mathrm{CDN}_{15}$ : the 15th percentile value of the range of $\mathrm{CDN}$ concentrations produced by any one aerosol number concentration. This value is always relative to a reference aerosol number concentration (See Fig. 4).

2. $\mathrm{CDN}_{85}$ : same as $\mathrm{CDN}_{15}$ but the 85 th percentile value.

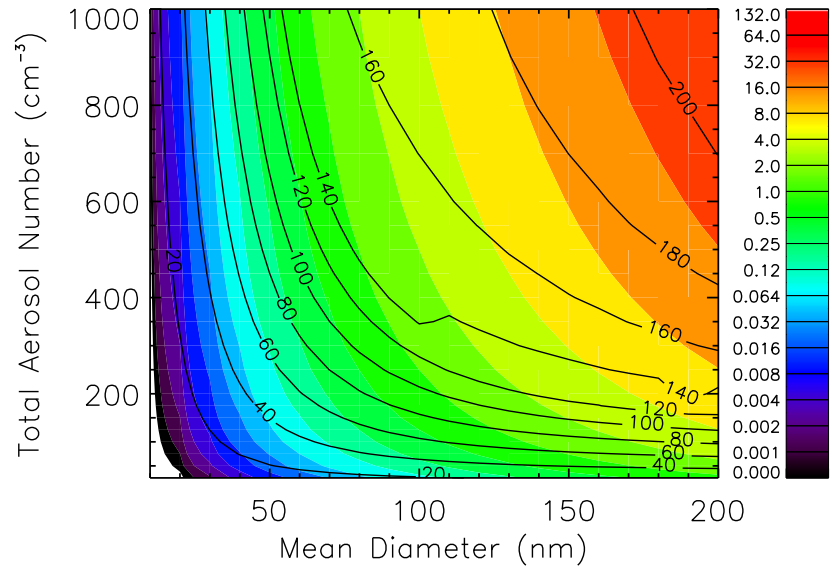

Fig. 5. $\mathrm{CDN}\left(\mathrm{cm}^{-3}\right)$ calculated for a range of lognormal ammonium sulfate aerosol distributions $(\sigma=1.8)$ with an updraft velocity of $0.15 \mathrm{~ms}^{-1}$, coloured contours indicate aerosol mass $\left(\mu \mathrm{g} \mathrm{m}^{-3}\right)$

High CDN concentrations occur (for a given aerosol number concentration) when the mean diameter of the accumulation mode is large and low CDN concentrations occur when the accumulation mode diameter is small. Thus, the variability in the CDN concentrations in Fig. 2 can be explained in terms of variations in the aerosol size distribution. Put another way, the CDN concentration is determined by both particle mass and number and if only one variable is used in a parameterisation then a large amount of physically explicable 

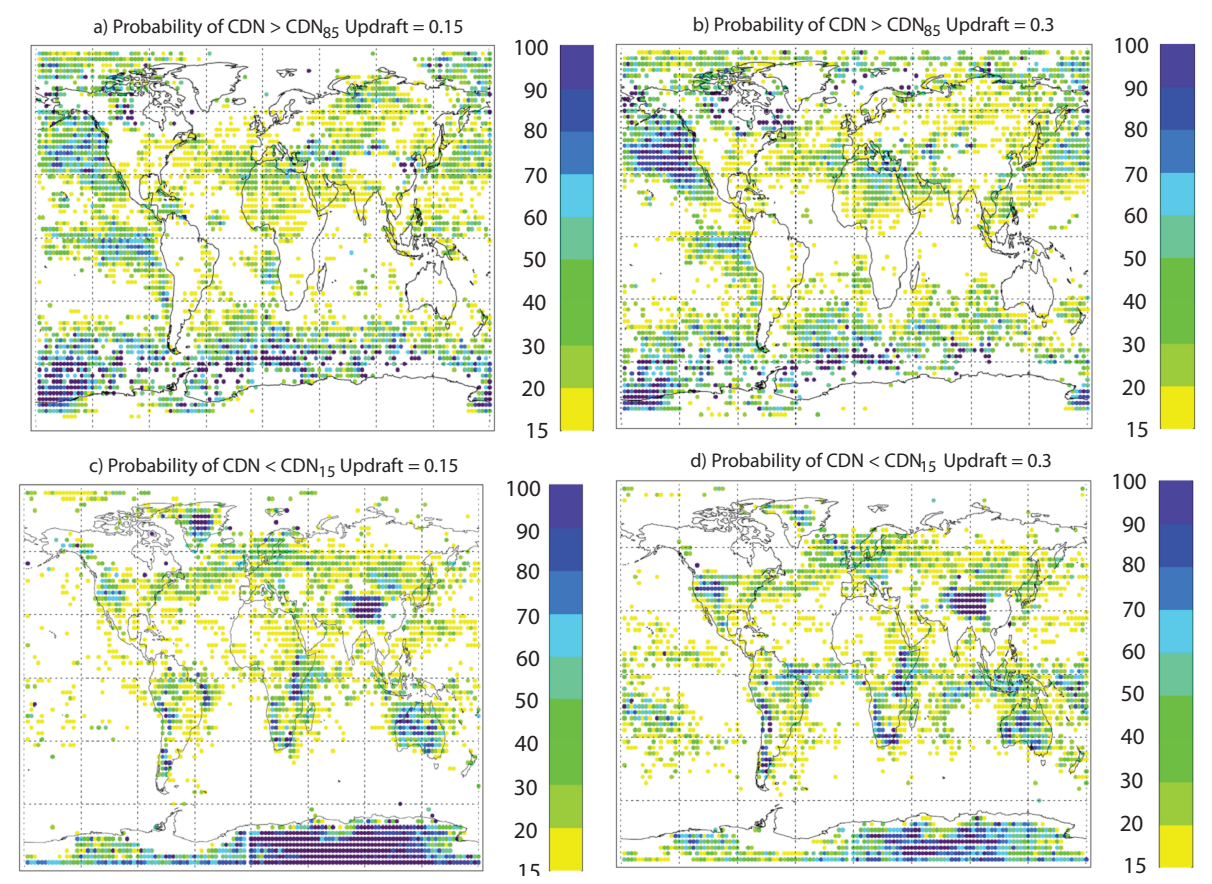

Fig. 6. The global distribution of the probability that the aerosol distribution in a particular grid-box will produce a CDN concentration that is (top row: $\mathbf{a}$ and $\mathbf{b})$ larger than the $85^{\text {th }}$ percentile $\left(\mathrm{CDN}_{85}\right)$ or (bottom row: $\mathbf{c}$ and $\mathbf{d}$ ) smaller than the 15 th percentile $\left(\mathrm{CDN}_{15}\right)$, of the range of CDN concentrations produced (for the relevant aerosol number concentration). Results are shown for an updraft velocity of 0.15 ms ${ }^{-1}$ (left column: a and c) and $0.3 \mathrm{~ms}^{-1}$ (right column: b and d).

variability will remain unaccounted for. This dependence of $\mathrm{CDN}$ on the particle size distribution has implications for the regional variation of CDN and the global applicability of single empirical relations, which we quantify below.

The contour plot in Fig. 5 helps to explain the codependence of CDN on aerosol size and number. The figure shows the contoured results of several hundred parcel model calculations of CDN assuming a log-normal accumulation mode (standard deviation $(\sigma)=1.8$ ) with varying size and number concentration. The equivalent aerosol specific mass is contoured in color. An increase in aerosol number for a fixed specific mass (moving right to left along a colored contour) leads to an increase in CDN. Likewise, an increase in specific aerosol mass for a fixed number (which implies an increase in the size of existing particles) also leads to an increase in CDN, because larger particles can be activated more easily. Observed correlations between aerosol mass or number and CDN arise from a combination of these two dependencies. Thus adding aerosol mass to the atmosphere can result in different changes in CDN depending on whether the mass appears as new particles or as growth of existing particles. For example, $200 \mathrm{~cm}^{-3}$ aerosol particles with a mode diameter of $50 \mathrm{~nm}$ results in a CDN concentration of $40 \mathrm{~cm}^{-3}$ (with an updraft velocity of $0.15 \mathrm{~ms}^{-1}$ ). Increasing the aerosol mass by a factor of 4 results in $\sim 100 \mathrm{~cm}^{-3}$ cloud drops if the new mass is added as new particles (of the same size), but only $\sim 70 \mathrm{~cm}^{-3}$ if mass is used to grow the existing particles (to $80 \mathrm{~nm}$ ). In general, except for very small particles $(<30-50 \mathrm{~nm})$, creation of new particles increases $\mathrm{CDN}$ more than growing existing particles (for the same mass added).

Therfore, to summarize, Fig. 5 shows that CDN is more sensitive to changes in aerosol number than size, but Figs. 2 and 3 confirm that the aerosol size distribution is also important. Thus although aerosol number is the main factor affecting CDN, knowledge of aerosol number alone is not sufficient to predict the range of CDN concentrations produced. Although previous studies have noted the importance of the accumulation mode diameter for CDN (e.g. McFiggans et al., 2006) our approach allows us to examine the importance of this dependence on a global scale (without other contributing factors).

\subsection{Probability distribution of relatively high/low CDN concentrations}

The dependence of $\mathrm{CDN}$ on the aerosol size distribution will be important if there are systematic differences in the size distribution between regions. Then the use of a globally uniform empirical relationship would produce regional biases, which may be important for forcing calculations. 

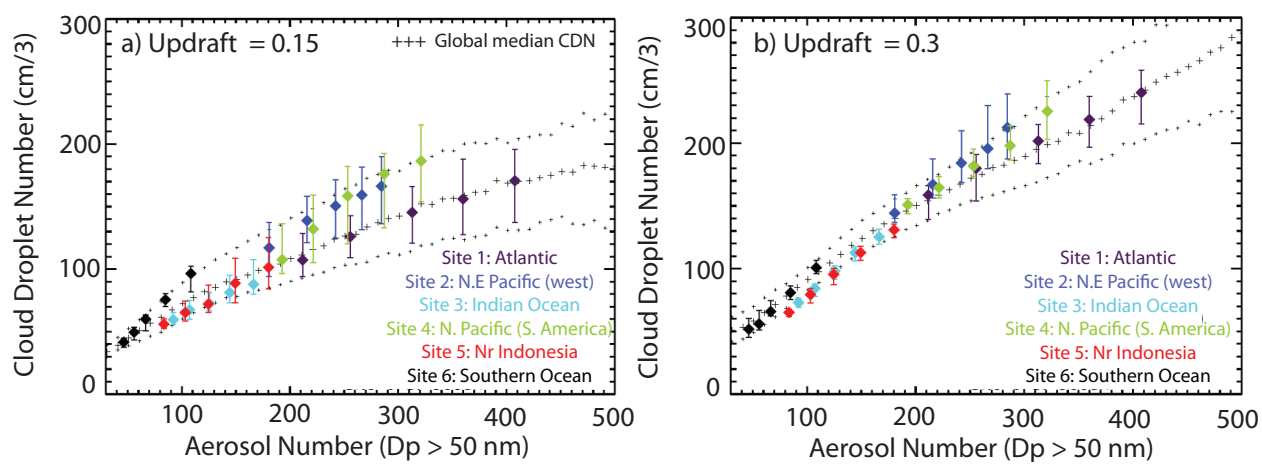

Fig. 7. Global median CDN concentrations for a range of aerosol number loadings (large black crosses); the smaller black crosses show the global $\mathrm{CDN}_{15}$ and $\mathrm{CDN}_{85}$ values. The over-plotted diamonds are the 30, 40, 50, 60 and 70th percentiles of the aerosol number concentrations in the sample region plotted against the regional median CDN concentration (for the relevant aerosol number concentration), error bars represent regional $\mathrm{CDN}_{15}$ and $\mathrm{CDN}_{85}$ values. Plots are shown for two updraft velocities (a) 0.15 and (b) $0.3 \mathrm{~ms}^{-3}$.

To illustrate the regional variability in $\mathrm{CDN}$ caused by variations in size distribution, Fig. 6 shows the probability of very high and very low CDN for a given aerosol number. Very high CDN is defined as greater than the 85th percentile global CDN concentration for a given aerosol number and very low as less than the 15th percentile. Note that it is not the absolute CDN that is shown, which will of course vary with aerosol number. Rather it is the probability of the CDN concentration being skewed to high or low values for a given aerosol concentration. In regions where there is no skew towards high or low CDN concentrations, the probability of $\mathrm{CDN}>\mathrm{CDN}_{85}$ (or $<\mathrm{CDN}_{15}$ ) is $15 \%$. In qualitative terms, Fig. 6 shows the global distribution of the influence of the aerosol size on $\mathrm{CDN}$.

The CDN concentration has a high probability of being larger than $\mathrm{CDN}_{85}$ in several marine regions: the persistent stratocumulus decks east of N America, S America, Africa, NW Pacific, and the sub-tropical Atlantic, as well as in the Southern Ocean. In these regions there is a $\geq 50 \%$ probability of the CDN concentration being larger than the 85th percentile. In these regions cloud cover is typically extensive and most particles are sufficiently aged for cloud processing to have shaped the aerosol distribution (contributing to the growth of the accumulation mode radius which facilitates subsequent cloud droplet formation). It is important to note that the same regions of high probability are predicted regardless of the updraft velocity used, implying that the difference arises due to systematic differences in the aerosol distribution rather than simply scatter.

Not all marine regions show a skew towards high CDN; in a narrow region around the inter-tropical convergence zone there is a high probability of CDN concentrations being less than $\mathrm{CDN}_{15}$. This region is subject to substantial aerosol wet removal and particles tend to be small and ineffective CCN. The polluted mid-latitude N. Atlantic also has a high probability of low $\mathrm{CDN}$ consistent with the relatively fresh small particles there.
CDN concentrations are likely to be below $\mathrm{CDN}_{15}$ in regions where aerosol are emitted, such as close to pollution sources (Europe, North America, Asia and Australia). High altitude regions and regions with low surface temperature such as the Himalayas, the Andes and Antarctica also have a high probability of CDN concentrations being $<\mathrm{CDN}_{15}$, possibly due to the low temperatures which can allow binary homogeneous $\mathrm{H}_{2} \mathrm{SO}_{4}-\mathrm{H}_{2} \mathrm{O}$ new particle formation to occur (Kulmala et al., 1998).

There is also a clear land / sea contrast in Fig. 6: 49\% of ocean boxes have a $\mathrm{CDN}$ concentration $>\mathrm{CDN}_{85}$ compared to just $16 \%$ of land grid boxes. Similarly, $20 \%$ of ocean grid boxes have a CDN concentration $<\mathrm{CDN}_{15}$, but $60 \%$ of land grid boxes produce a $\mathrm{CDN}$ concentration that is in the lowest 15th percentile $\left(\mathrm{CDN}_{15}\right)$. Thus we find that for the same total aerosol number (and updraft velocity), marine aerosol distributions - especially those in regions where low cloud cover is extensive - typically produce larger CDN concentrations. We conclude that this is due to the ability of the cloud decks to contribute to the growth of the mean diameter of the accumulation mode - producing aerosol particles that are more able to contribute to cloud droplet formation.

\subsection{Regional aerosol number/CDN relationships}

The previous section showed that there is large regional variability in the ability of aerosol to activate into cloud droplets. Ramanathan et al. (2001) showed that the aerosol number/CDN relationship varies between regions, but this was based on observations where many factors can contribute (e.g. updraft, particle size or chemical composition), thus it is difficult to determine the source of this variance. Here we derive equivalent empirical relations by sampling aerosol number and calculated CDN from different model regions. 

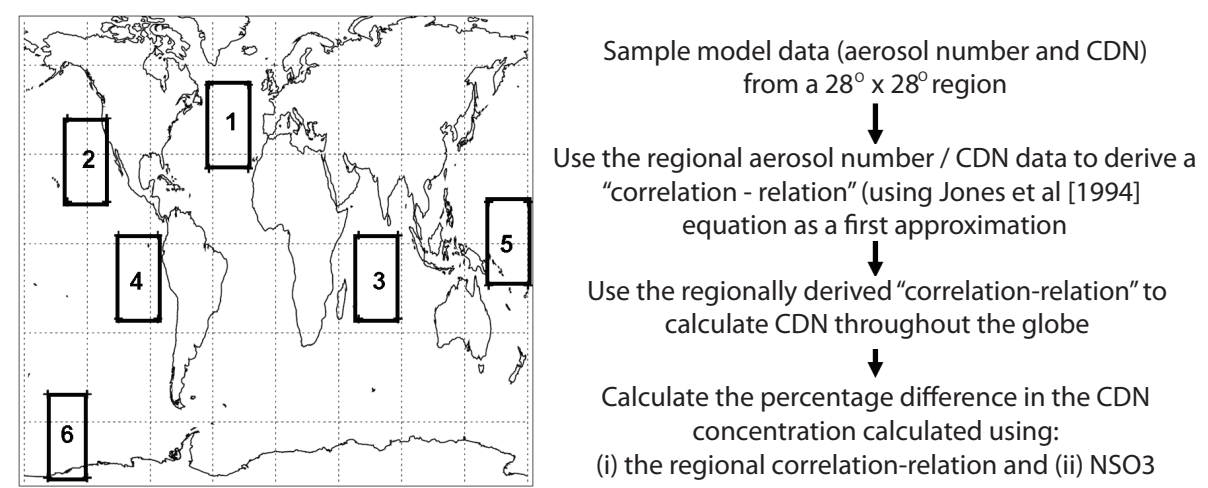

Fig. 8. Schematic showing the 6 regions sampled in the study (left) and an overview of the process by which the plots in Fig. 10 are produced (right).
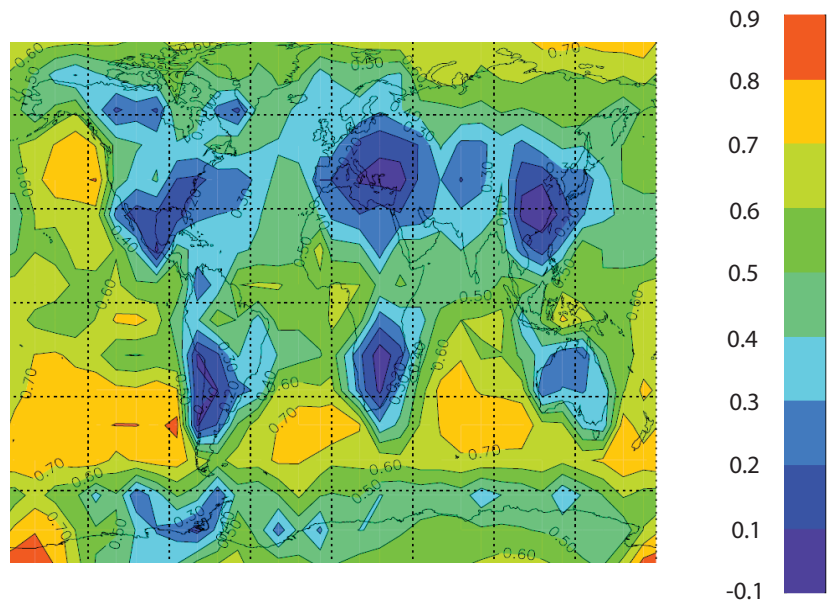

Fig. 9. Global distribution of the gradient $\partial \mathrm{CDN} / \partial \mathrm{N}_{a}$ $\left(\mathrm{N}_{a}=\right.$ aerosol particle number). Results are based on a linear regression of CDN vs aerosol number. Each gradient value is calculated from data sampled from regions of 4 neighboring grid boxes. An updraft velocity of $0.3 \mathrm{~ms}^{-1}$ was used.

Figure 7 shows the median CDN concentrations versus aerosol number in 6 geographical regions (see Fig. 8), with error bars indicating 15th and 85th percentiles. These geographical regions were chosen as; (i) they give reasonable coverage of marine regions, and (ii) they showed a range of different probabilities of producing high/low CDN concentrations (for a given aerosol number concentration, Fig. 6). Also shown for comparison is the global median CDN concentration (and percentiles). Two things are clearly apparent. Firstly, as was shown in the previous section, the median $\mathrm{CDN}$ relation for some regions lies far from the global median. For example, the Southern Ocean median lies near the global 85th percentile. The N. Atlantic region lies closest to the global median, although as shown previously the Atlantic has regions of both higher and lower than average CDN. Secondly, the gradient $\partial \mathrm{CDN} / \partial \mathrm{N}_{a}$ (where $\mathrm{N}_{a}=$ the aerosol number) varies greatly between regions. This is shown more clearly as a map in Fig. 9, which shows that $\partial \mathrm{CDN} / \partial \mathrm{N}_{a}$ varies by a more than a factor 4 between regions.

The regional variation in $\partial \mathrm{CDN} / \partial \mathrm{N}_{a}$ has implications for calculations of the indirect effect based on empirical relations. For example, sampling data from the N.E. Pacific to produce an empirical relation will result in a steeper aerosol number / CDN relation - and thus a larger aerosol indirect effect - than a relation derived from the N. Atlantic. In the low updraft scenario (Fig. 7a), increasing aerosol number from 200 to $300 \mathrm{~cm}^{-3}$ increases CDN by $30 \%$ in the N. Atlantic, but the same increase produces an increase in $\mathrm{CDN}$ of $>55 \%$ in the N. Pacific.

Figure 9 shows that $\mathrm{CDN}$ in regions of low stratocumulus, which are most important for indirect forcing, are highly sensitive to changes in aerosol due to the high efficacy of the $\mathrm{CCN}$ there. The indirect forcing will tend to be underestimated if empirical relations from less cloudy regions are used.

\section{Application of a regionally derived relation to the pre- diction of global fields of CDN}

Due to the difficulties involved in taking measurements, empirical relations are derived from observations in a limited area. For example, Menon et al. (2002) used observations from the $\mathrm{N}$. Atlantic and the Canary Islands alone and Boucher and Lohmann (1995) used observations from $\mathrm{N}$. America and the N. Atlantic regions only. The relationship of Jones et al. (1994) is based on the measurements in the eastern Pacific, the South Atlantic, subtropical regions of the North Atlantic, and marine areas near the UK (Martin et al., 1994). We now quantify how predictions based on extrapolated regional empirical relations compare with locally predicted CDN. 

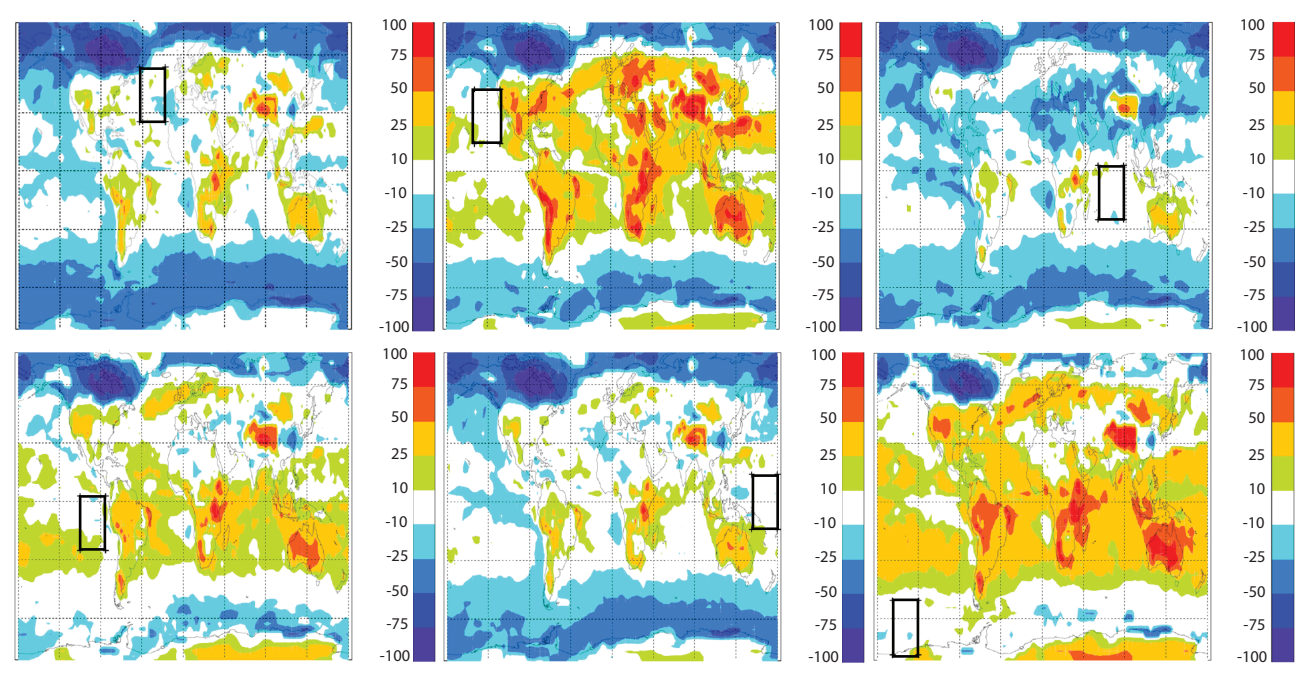

Fig. 10. Percentage difference in $\mathrm{CDN}$ that occurs when global $\mathrm{CDN}$ is calculated using a correlation relationship derived from regional $\mathrm{CDN}$ concentrations (compared to the NS03 parameteriation). Each plot corresponds to biases calculated from correlation-relations derived from data in the six study regions (1-6 shown from top to bottom, location shown by the black rectangle). An updraft velocity of 0.15 ms ${ }^{-1}$ is used.

CDN fields based on the parameterisation of NS03 were used to calculate aerosol number-CDN relationships for regions of the globe analogous to the creation of empirical relationships from observational data. An overview of the procedure is given in Fig. 8. Model data were sampled from six $28^{\circ} \times 28^{\circ}$ marine regions over 15 days using $6 \mathrm{~h}$ averaged data. A short time period (15 days) was deliberately chosen as this is approximately the length of a typical flight-based field campaign and we wished to eliminate the contribution of seasonal variability. The empirical relation of Jones et al. (1994) was used to fit the data:

$\mathrm{CDN}=N_{0}\left(1-\exp \left[-A N_{a}\right]\right)$

with the coefficients $N_{0}$ and $A$ (375 and -0.0025 in Jones et al. (1994)) as fit parameters (and $\mathrm{N}_{a}$ being the aerosol number concentration). Two correlation relationships were derived for each region; one where updraft velocity in the NS03 calculation was set to $0.15 \mathrm{~ms}^{-1}$ and the other to $0.3 \mathrm{~ms}^{-1}$. We call our derived number-CDN relationships "correlation relationships" rather than empirical relationships as they are derived from model data rather than observations.

Figure 10 shows the percentage bias in $\mathrm{CDN}$ arising from the use of the regional correlation relationships compared to fields calculated using the NS03 scheme and local aerosol size distributions.

Bias $=\left(\left(\mathrm{CDN}_{\text {Correlation }}-\mathrm{CDN}_{\mathrm{NS} 03}\right) / \mathrm{CDN}_{\mathrm{NS} 03}\right) * 100.0(2)$

A negative bias corresponds to the correlation-relation underestimating CDN. A T-test was used to identify significant biases within the scatter of the model at the $95 \%$ confidence level and only those values are shown.

It is clear from Fig. 10 that regionally derived aerosol number / CDN relationships produce global fields of CDN that are significantly different from those predicted using local aerosol size distributions and the mechanistic approach. Thus because the aerosol size distribution varies throughout the globe, aerosols may be more or less able to activate in particular regions. The use of a single (regionally derived) relationship applied throughout the globe cannot capture this detail, thus it leads to biases compared to a calculation of CDN which takes the aerosol size distribution in each individual grid box into account (i.e. NS03). Biases in CDN of $>10 \%$ are quite common and some relationships produce a bias of 25 to $>50 \%$ in certain regions. The pattern of bias is complex but a number of key points can be made:

1. In Fig. 7 the N. Atlantic was shown to have a dependence of CDN on aerosol number similar to the global average (within the range of aerosol number concentrations in the region). Extrapolating from this region does well in some regions, but fails to capture the higher than average CDN concentrations in regions where cloud processing is extensive (leading to $10-25 \%$ biases). It also fails to capture the lower than average CDN concentrations in some continental regions (see Figure 6).

2. The magnitude of the bias depends on whether the correlation was derived from a region with high or low $\mathrm{CDN}$ (for the given aerosol loading, see Fig. 6): Regions 2, 4 and 6 (N. E. Pacific, E. Pacific and the S. Ocean) have a high probability of producing a larger 
Table 1. Summary of global mean CDN concentrations calculated using the two methods. "Updraft": Updraft velocity used for NS03; "CDN NS03": Global average CDN concentration for the two updraft velocities, calculated using NS03; "Region": Region used to derive the regionally-derived correlation relations; "CDN Corr": Global average CDN calculated using the regionally-derived correlation relations; "Abs Diff" (or \% Diff): The global mean absolute (or \%) difference in CDN between the two calculations of CDN (weighted by gridbox area and low cloud cover from ISCCP). All CDN concentrations are in $\mathrm{cm}^{-3}$, regions defined in Fig. 8.

\begin{tabular}{cccccc}
\hline $\begin{array}{c}\text { Updraft } \\
\left(\mathrm{ms}^{-1}\right)\end{array}$ & $\begin{array}{c}\text { CDN } \\
\text { NS03 }\end{array}$ & Region & $\begin{array}{c}\text { CDN } \\
\text { Corr. }\end{array}$ & $\begin{array}{c}\text { Abs. } \\
\text { Diff }\end{array}$ & $\begin{array}{c}\% \\
\text { Diff }\end{array}$ \\
\hline 0.15 & 95 & 1 & 88 & 23 & 17 \\
0.15 & 95 & 2 & 108 & 31 & 21 \\
0.15 & 95 & 3 & 79 & 24 & 18 \\
0.15 & 95 & 4 & 98 & 23 & 20 \\
0.15 & 95 & 5 & 89 & 21 & 19 \\
0.15 & 95 & 6 & 112 & 31 & 25 \\
0.30 & 139 & 1 & 124 & 27 & 23 \\
0.30 & 139 & 2 & 148 & 36 & 27 \\
0.30 & 139 & 3 & 114 & 32 & 20 \\
0.30 & 139 & 4 & 144 & 33 & 21 \\
0.30 & 139 & 5 & 126 & 27 & 21 \\
0.30 & 139 & 6 & 137 & 36 & 31 \\
\hline
\end{tabular}

than average $\mathrm{CDN}$, thus correlations derived from these regions overestimate $\mathrm{CDN}$ in regions that do not have this bias towards high CDN. In the case of the N.E. Pacific relationship, this leads to an overestimation of CDN of 10-25\% over much of the Atlantic and most continental regions, with biases of $25-50 \%$ also predicted.

3. In Fig. 6, regions 3 and 5 (Indian Ocean and near Indonesia) were shown to be more likely to produce lower than average $\mathrm{CDN}$ concentrations. Extrapolating these aerosol number/CDN relationships to the global scale therefore leads to a large-scale underestimation of (especially marine) $\mathrm{CDN}$.

4. CDN over the Southern Ocean are consistently underpredicted by $25-50 \%$ except when the local correlation relation is used. This is important as cloud cover is typically extensive in the Southern Ocean.

An additional point is that all correlation relations underpredict CDN in the Arctic, sometimes by as much as $75 \%$. Simulating the Arctic aerosol is a tough challenge for aerosol models as it is a region dominated by long range transport with a complex meteorology and relatively few observations. Korhonen et al. (2008) examined the performance of the GLOMAP model in the Arctic region and found that the model consistently under predicts aerosol loading in the Arctic and is only partially able to capture the Arctic spring haze. This has implications for the calculation of CDN in this region as the low aerosol concentrations mean that there is very little competition for the available water vapor, thus aerosol can activate down to very small sizes (e.g. Komppula et al., 2005). In the calculation of the correlation relationships, aerosol number was only counted for particles $>50 \mathrm{~nm}$ diameter (following Jones et al. (2001)), but in regions of extremely low aerosol loading a significant fraction of the activated particles are smaller than $50 \mathrm{~nm}$. Under these conditions, empirical relations derived from other locations do not work well because of the fixed minimum diameter assumed. The under-prediction of Arctic aerosol concentrations in the model will exaggerate this effect. Thus, the differences between the mechanistic and empirical calculations are likely to be an upper estimate. Table 1 shows the global mean CDN concentration calculated with the mechanistic and regionally derived correlation relationships. Note this is a global mean $\mathrm{CDN}$, thus for the NS03 case just two values are given (corresponding to the two updrafts considered). The fourth column shows the global mean CDN concentration calculated using the various regionally-derived correlation relations. The fifth column gives the absolute global mean difference in CDN between the NS03 and the correlation scenarios, weighted by the monthly mean low cloud fraction and grid-box area. The correlation relations derived from the N. Atlantic and near Indonesia (regions 1 and 5) give the smallest consistent global mean absolute error with values of approximately $22 \mathrm{~cm}^{-3}$ at the lower updraft velocity and $27 \mathrm{~cm}^{-3}$ at the higher. The N.E. Pacific and the Southern Ocean relations give the largest error ( 31 and $36 \mathrm{~cm}^{-3}$ for the 2 updrafts). To place these absolute changes in context, the area and cloud weighted change in CDN arising from a doubling of the updraft velocity (from 0.15 to $0.3 \mathrm{~ms}^{-1}$ ) is $54 \mathrm{~cm}^{-3}$. Thus, the global mean error caused by the use of a single empirical relationship is approximately half of that caused by a factor of 2 change in the updraft velocity. However, on a regional scale the biases are much larger, as was shown in Fig. 10.

\section{Conclusions}

This paper has used the physically based aerosol activation scheme of Nenes and Seinfeld (2003) coupled to a sectional global aerosol model (GLOMAP) to examine the ability of number-based empirical relationships to calculate global fields of CDN. We find that although many studies have used these relationships well in the past, there are basic physical limitations of empirical schemes that cause systematic biases in the simulated CDN fields. We find that the probability of a given aerosol number concentration producing a relatively high/low CDN concentration has a distinct global pattern that can be explained in terms of predictable variations in the aerosol size distribution. CDN concentrations are much higher than predicted by empirical relations in strongly cloud processed regions and are lower than predicted empirically 
where aerosol are newly formed. In regions of persistent stratocumulus cloud the predicted CDN concentrations for a given aerosol number exceed the global 85 th percentile more than $50 \%$ of the time. In these regions frequent processing of aerosol through clouds produces large CCN that produce higher droplet concentrations for a given aerosol number. The extrapolation of aerosol number/CDN correlations taken from particular regions to the global scale leads to systematic biases in the CDN fields produced. For example, North Atlantic observations have been used to generate empirical aerosol number/CDN relationships (e.g. Menon et al., 2002). When an aerosol-CDN relation is generated in a similar way in our model it leads to regional biases of up to $50 \%$ in CDN. The Arctic, the Southern Ocean and regions of persistent stratocumulus cloud show the greatest biases. There is also very large regional variation (up to a factor 4 ) in the sensitivity of CDN to changes in aerosol $\left(\partial \mathrm{CDN} / \partial \mathrm{N}_{a}\right)$. Again, the Southern Ocean and regions of persistent stratocumulus are particularly sensitive. Thus, the error in predicted CDN and in the response of CDN to changes in aerosol using an empirical relation maximizes in regions that account for most of the global first indirect forcing in climate models. Errors in the Arctic are also of concern given that it is a region highly susceptible to climate change.

Although this study is limited to sea spray and sulfate aerosol, we can expect that the increased complexity of a more realistic aerosol system will add extra dimensions to the complexity and will provide additional variations that empirical relations will struggle to capture. Here we have drawn attention to the importance of the aerosol size distribution and certain processes that shape it.

Although mechanistic CDN schemes are generally considered to be ideologically preferable (Lohmann and Feichter, 2005), we know of no work that has shown them to be superior to empirical schemes in terms of their explanatory power. In fact, Menon et al. (2003) found that in a single column model, mechanistic activation schemes performed no better than empirical schemes compared to observations due to problems in diagnosing updraft velocity. However, we have shown that empirical schemes produce large regional errors that can be explained in terms of variations in aerosol physical properties.

Despite the difficulties associated with mechanistic schemes in climate models (primarily defining updraft speeds) our results suggest that such schemes should have some regional explanatory power that is not captured by variations in aerosol mass or number alone. A careful analysis of CDN observations in different regions and a comparison against empirical predictions may confirm this.

Acknowledgements. The authors would like to thanks A. Jones for his helpful comments and A. Nenes for help with implementing the parameterisation. KJP was supported by a NERC studentship and DVS by a NERC Universities Global Atmospheric Modelling Programme studentship.
The service charges for this open access publication have been covered by the Max Planck Society.

Edited by: J. Quaas

\section{References}

Abdul-Razzak, H. and Ghan, S. J.: A parameterization of aerosol activation, 2, Multiple aerosol types, J. Geophys. Res.-Atmos., 105, 6837-6844, doi:10.1029/1999JD901161, 2000.

Abdul-Razzak, H. and Ghan, S. J.: A parameterization of aerosol activation 3. Sectional representation, J. Geophys. Res.-Atmos., 107, 4026, doi:10.1029/2001JD000483, 2002.

Abdul-Razzak, H., Ghan, S. J., and Rivera-Carpio, C.: A parameterization of aerosol activation 1. Single aerosol type, J. Geophys. Res.-Atmos., 103, 6123-6132, doi:10.1029/97JD03735, 1998.

Adams, P. and Seinfeld, J.: Disproportionate impact of particulate emissions on global cloud condensation nuclei concentrations, Geophys. Res. Lett., 30, 43-46, 2003.

Andreae, M. O. and Rosenfeld, D.: Aerosol-cloud-precipitation interactions. Part 1. The nature and sources of cloud-active aerosols, Earth. Sci. Rev., 89, 13-41, doi:10.1016/j.earscirev. 2008.03.001, 2008.

Bauer, E., Petoukhov, V., Ganopolski, A., and Eliseev, A.: Climatic response to anthropogenic sulphate aerosols versus well-mixed greenhouse gases from 1850 to 2000 AD in CLIMBER-2, J. Geophys. Res.-Atmos., 60, 82-97, 2008.

Benkovitz, C.: Global gridded inventories of anthropogenic emissions of sulfur and nitrogen, J. Geophys. Res.-Atmos., 101, 29239-29253, 1996.

Bennartz, R.: Global assessment of marine boundary layer cloud droplet number concentration from satellite, J. Geophys. Res.Atmos., 112, D02201, doi:10.1029/2006JD007547, 2007.

Boucher, O. and Lohmann, U.: The sulfate-CCN-cloud. albedo effect, A sensitivity study with two general circulation models, Tellus Ser. B., 47, 281-300, 1995.

Chen, Y. and Penner, J. E.: Uncertainty analysis for estimates of the first indirect aerosol effect, Atmos. Chem. Phys., 5, 2935-2948, 2005, http://www.atmos-chem-phys.net/5/2935/2005/.

Chipperfield, M.: New Version of the TOMCAT/SLIMCAT OffLine Chemical Transport Model: Intercomparison of Stratospheric Tracer Experiments, Q. J. Roy. Meteor. Soc., 132, 11791203, doi:10.1256/qj.05.51, 2006.

Chuang, C., Penner, J., Prospero, J., Grant, K., Rau, G., and Kawamoto, K.: Cloud susceptibility and the first aerosol indirect forcing: Sensitivity to black carbon and aerosol concentrations, J. Geophys. Res.-Atmos., 107(D21), doi:10.1029/2000JD000215, 2002.

Dusek, U., Frank, G. P., Hildebrandt, L., Curtius, J., Schneider, J., Walter, S., Chand, D., Drewnick, F., Hings, S., Jung, D., Borrmann, S., and Andreae, M. O.: Size Matters More Than Chemistry for Cloud-Nucleating Ability of Aerosol Particles, Science, 312, 1375-1378, doi:10.1126/science.1125261, 2006.

Forster, P., Ramaswamy, V., Artaxo, P., Berntsen, T., Betts, R., Fahey, D., Haywood, J., Lean, J., Lowe, D., Myhre, G., Nganga, J., Prinn, R., Raga, G., Schulz, M., and Van Dorland, R.: Climate Change 2007: The Physical Science Basis. Contribution of Working Group I to the Fourth Assessment Report of the Inter- 
governmental Panel on Climate Change, Cambridge University Press, 2007.

Fountoukis, C. and Nenes, A.: Continued Development of a Cloud Droplet Formation Parameterization for Global Climate Models, J. Geophys. Res.-Atmos., 110, D11212, doi:10.1029/ 2004JD005591, 2005.

Fountoukis, C., Nenes, A., Meskhidze, N., Bahreini, R., Conant, W. C., Jonsson, H. Murphy, S., Sorooshian, A., Varutbangkul, V., Brechtel, F., Flagan, R. C., and Seinfeld, J. H.: Aerosol cloud drop concentration closure for clouds sampled during the International Consortium for Atmospheric Research on Transport and Transformation 2004 campaign, J. Geophys. Res.-Atmos., 112, D10S30, doi:10.1029/2006JD007272, 2007.

Ghan, S., Easter, R., Hudson, J., and Breon, F.-M.: Evaluation of aerosol indirect radiative forcing in MIRAGE, J. Geophys. Res.Atmos., 106, 5317-5334, 2001.

Gultepe, I. and Isaac, G. A.: Scale effects on averaging of cloud droplet and aerosol number concentrations: observations and models, J. Climate, 12, 1268-1279, 1999.

Hallberg, A., Noone, K. J., and Ogren, J. A.: Aerosol particles and clouds: which particles form cloud droplets?, Tellus. B, 50, 5975, 1998.

Jones, A., Roberts, D., and Slingo, A.: A climate model study of indirect radiative forcing by anthropogenic sulfate aerosols, Nature, 370, 450-453, 1994.

Jones, A., Roberts, D., Woodage, M., and Johnson, C.: Indirect sulphate aerosol forcing in a climate model with an interactive sulphur cycle, J. Geophys. Res.-Atmos., 106, 20293-20310, 2001.

Kiehl, J., Schneider, T. L., Rasch, P. J., Barth, M. C., and Wong, J.: Radiative forcing due to sulfate aerosols from simulations with the National Center for Atmospheric Research Community Climate Model, version 3, J. Geophys. Res.-Atmos., 105, 14411458, 2000.

Kirkevag, A., Iversen, T., Kristjansson, J. E., Seland, Ø., and Debernard, J. B.: On the additivity of climate response to anthropogenic aerosols and $\mathrm{CO} 2$, and the enhancement of future global warming by carbonaceous aerosols, Tellus A, 60A, 513-527, 2008.

Komppula, M., Lihavainen, H., Kerminen, V. M., Kulmala, M., and Viisanen, Y.: Measurements of cloud droplet activation of aerosol particles at a clean subarctic background site, J. Geophys. Res.-Atmos., 110, D06204, doi:http://dx.doi.org/10.1029/ 2004JD005200, 2005.

Korhonen, H., Carslaw, K. S., Spracklen, D. V., Mann, G., and Woodhouse, M.: Influence of oceanic DMS emissions on CCN concentrations and seasonality over the remote southern hemisphere oceans: A global model study, J. Geophys. Res.-Atmos., 113(D12), doi:10.1029/2007JD009718, 2008.

Kristjansson, J. E.: Studies of the aerosol indirect effect from sulfate and black carbon aerosols, J. Geophys. Res.-Atmos., 107(D15), doi:10.1029/2001JD000887, 2002.

Kristjansson, J. E., Iversen, T., Kirkevåg, A., Seland, Ø., and Debernard, J.: Response of the climate system to aerosol direct and indirect forcing: Role of cloud feedbacks, J. Geophys. Res.Atmos., 110, D24206, doi:10.1029/2005JD006299, 2005.

Kulmala, M., Laaksonen, A., and Pirjola, L.: Parameterization for sulfuric acid/water nucleation rates, J. Geophys. Res.-Atmos., 103, 8301-8307, 1998.

Lohmann, U. and Feichter, J.: Global indirect aerosol effects: a review, Atmos. Chem. Phys., 5, 715-737, 2005, http://www.atmos-chem-phys.net/5/715/2005/.

Lohmann, U., Feichter, J., Chuang, C. C., and Penner, J. E.: Prediction of the number of cloud droplets in the ECHAM GCM, J Geophys. Res.-Atmos., 104, 9169-9198, 1999.

Lohmann, U., Feichter, J., Penner, J., and Leaitch, R.: Indirect effect of sulfate and carbonaceous aerosols: A mechanistic treatment, J. Geophys. Res.-Atmos., 105, 12193-12206, doi: 10.1029/1999JD901199, 2000.

Lowenthal, D. H., Borys, R. D., Choularton, T. W., Bower, K. N., Flynn, M. J., and Gallagher, M. W.: Parameterization of the cloud droplet-sulfate relationship, Atmos. Environ., 38, $287-$ 292, 2004.

Ma, X., von Salzen, K., and Li, J.: Modelling sea salt aerosol and its direct and indirect effects on climate, Atmos. Chem. Phys., 8, 1311-1327, 2008, http://www.atmos-chemphys.net/8/1311/2008/.

Martin, G., Johnson, D., and Spice, A.: The measurement and parameterization of effective radius of droplets in warm stratiform clouds, J. Atmos. Sci., 51, 1823-1842, 1994.

McComiskey, A. and Feingold, G.: Quantifying error in the radiative forcing of the first aerosol indirect effect, Geophys. Res. Lett., 35, L02810, doi:10.1029/2007GL032667, 2008.

McFiggans, G., Artaxo, P., Baltensperger, U., Coe, H., Facchini, M. C., Feingold, G., Fuzzi, S., Gysel, M., Laaksonen, A., Lohmann, U., Mentel, T. F., Murphy, D. M., O’Dowd, C. D., Snider, J. R., and Weingartner, E.: The effect of physical and chemical aerosol properties on warm cloud droplet activation, Atmos. Chem. Phys., 6, 2593-2649, 2006, http://www.atmos-chem-phys.net/6/2593/2006/.

Menon, S. and Rotstayn, L.: The radiative influence of aerosol effects on liquid-phase cumulus and stratiform clouds based on sensitivity studies with two climate models, Climate Dynam., 27(4), doi:10.1007/s00382-006-0139-3, 2007.

Menon, S., Del Genio, A. D., Dorothy, K., and Tselioudis, G.: GCM simulations of the aerosol indirect effect: Sensitivity to cloud parameterization and aerosol burden, J. Atmos. Sci., 59, 692713, 2002.

Menon, S., Brenguier, J.-L., Boucher, O., Davison, P., Del Genio, A. D., Feichter, J., Ghan, S., Guibert, S., Liu, X., Lohmann, U., Pawlowska, H., Penner, J. E., Quaas, J., Roberts, D. L., Schuller, L., and Snider, J.: Evaluating aerosol/cloud/radiation process parameterizations with single-column models and Second Aerosol Characterisation Experiment (ACE-2) cloudy column observations, J. Geophys. Res., 108(D24), doi:10.1029/2003JD003902, 2003.

Meskhidze, N., Nenes, A., Conant, W. C., and Seinfeld, J.: Evaluation of a new Cloud Droplet Activation Parameterization with In Situ Data from CRYSTAL-FACE and CSTRIPE, J. Geophys. Res.-Atmos., 110, D16202, doi:10.1029/2004JD005703, 2005.

Meskhidze, N., Sotiropoulou, R. E. P., Nenes, A., Kouatchou, J., Das, B., and Rodriguez, J. M.: Aerosol-cloud interactions in the NASA GMI: model development and indirect forcing assessments, Atmos. Chem. Phys. Discuss., 7, 14295-14330, 2007, http://www.atmos-chem-phys-discuss.net/7/14295/2007/.

Ming, Y., Ramaswamy, V., Ginoux, P. A., Horowitz, L. W., and Russell, L. M.: Geophysical Fluid Dynamics Laboratory general circulation model investigation of the indirect radiative effects of anthropogenic sulfate aerosol, J. Geophys. Res.-Atmos., 110, 
D22206, doi:10.1029/2005JD006161, 2005.

Ming, Y., Ramaswamy, V., Donner, L. J., and Phillips, V. T. J.: A new parameterization of cloud droplet activation applicable to general circulation models, J. Atmos. Sci., 63, doi:10.1175/ JAS3686.11348-1356, 2006.

Nenes, A. and Seinfeld, J. H.: Parameterization of cloud droplet formation in global climate models, J. Geophys. Res.-Atmos., 108(4415), doi:10.1029/2002JD002911, 2003.

Penner, J. E., Quass, J., Storelvmo, T., Takemura, T. Boucher, O., Guo, H., Kirkevag, A., Kristjansson, J. E., and Seland, O.: Model intercomparision of indirect aerosol effects, Atmos. Chem. Phys., 6, 3391-3405, 2006, http://www.atmos-chem-phys.net/6/3391/2006/.

Quaas, J., Boucher, O., and Lohmann, U.: Constraining the total aerosol indirect effect in the LMDZ and ECHAM4 GCMs using MODIS satellite data, Atmos. Chem. Phys., 6, 947-955, 2006, http://www.atmos-chem-phys.net/6/947/2006/.

Ramanathan, V., Crutzen, P., Kiehl, J., and Rosenfeld, D.: Atmosphere - Aerosols, climate, and the hydrological cycle, Science, 294, 2119-2124, 2001.

Rotstayn, L. D., Cai, W., Dix, M. R., Farquhar, G. D., Feng, Y., Ginoux, P., Herzog, M., Ito, A., Penner, J., Roderick, M. L., and Wang, M.: Have Australian rainfall and cloudiness increased due to the remote effects of Asian anthropogenic aerosols?, J. Geophys. Res.-Atmos., 112, D09202, doi:10.1029/2006JD007712, 2007.

Spracklen, D., Pringle, K., Carslaw, K., Chipperfield, M., and Mann, G.: A global off-line model of size resolved aerosol processes; I. Model development and prediction of aerosol properties, Atmos. Chem. Phys., 5, 2227-2252, 2005 a.
Spracklen, D., Pringle, K., Carslaw, K., Chipperfield, M., and Mann, G.: A global off-line model of size resolved aerosol processes; II. Importance of uncertainties in microphysical processes, Atmos. Chem. Phys., 5, 3233-3250, 2005 b.

Spracklen, D. V., Carslaw, K. S., Kulmala, M., Kerminen, V.-M., Mann, G. W., and Sihto, S.-L.: The contribution of boundary layer nucleation events to total particle concentrations on regional and global scales, Atmos. Chem. Phys., 6, 5631-5648, 2006, http://www.atmos-chem-phys.net/6/5631/2006/.

Spracklen, D. V., Pringle, K. J., Carslaw, K. S., Mann, G. W., Manktelow, P., and Heintzenberg, J.: Evaluation of a global aerosol microphysics model against size-resolved particle statistics in the marine atmosphere, Atmos. Chem. Phys., 7, 2073-2090, 2007, http://www.atmos-chem-phys.net/7/2073/2007/.

Stockwell, D. and Chipperfield, M.: A tropospheric chemical transport model : Development and validation of the model transport schemes, Q. J. Roy. Meteorol. Soc., 125, 1747-1783, 1999.

Takemura, T., Nozawa, T., Emori, S., Nakajima, T. Y., and Nakajima, T.: Global three-dimensional simulation of aerosol optical thickness distribution of various origins, J. Geophys. Res.Atmos., 110, 17853-17874, doi:10.1029/2004JD005029, 2005.

Verma, S., Boucher, O., Upadhyaya, H., and Sharma, O.: Sulfate aerosols forcing: An estimate using a three-dimensional interactive chemistry scheme, Atmos. Environ., 40, 7953-7962, 2006.

Zhang, Y., Easter, R. C., Ghan, S. J., and Abdul-Razzak, H.: Impact of aerosol size representation on modeling aerosol-cloud interactions, J. Geophys. Res.-Atmos., 107, 4558, doi:10.1029/ 2001JD001549, 2002. 